APR1400 안전관련계통 정비효과감시 프로그램 개발

염 동운 ${ }^{\dagger}$ 현진우 · 송태영

한국수력원자력(주)

(2014년 5월 18일 접수, 2014년 6월 19일 수정, 2014년 6월 20일 채택)

\title{
Development of Maintenance Effectiveness Monitoring Program for APR1400 Safety Related Systems
}

\author{
Dong Un Yeom ${ }^{\dagger} \cdot$ Jin Woo Hyun · Tae Young Song \\ Korea Hydro \& Nuclear Power Co.
}

(Received 18 May 2014, Revised 19 June 2014, Accepted 20 June 2014)

요약

\begin{abstract}
국내 가동중 원전은 발전소 안전성 및 신뢰성을 향상시킬 목적으로 정비효과감시 프로그램(정비규 정)을 개발하여 2009년부터 이행 중에 있다. 정비효과감시 프로그램은 발전소 전 계통을 기능단위로 분류한 후 관리대상 선정, 안전중요도 결정 및 성능기준 수립을 통해 발전설비의 정비효과를 감시하는 프로그램이며, NUMARC 93-01 방법론을 기반으로 발전소별 고유 설계특성을 반영하여 개발하고 있다. 최근 건설 중인 APR1400형 원전도 운영초기 단계부터 정비체계 정착을 목적으로 안전관련계통 정비효과감시 프로그램을 개발하였으며, 향후 초기 성능평가를 통해 프로그램의 적합성을 검증할 예 정이다. 결과적으로 고유 설계특성을 반영하여 개발한 정비효과감시 프로그램의 이행을 통해 APR1400형 원전의 안전성 및 신뢰성이 향상될 것으로 기대된다.
\end{abstract}

주요어 : 정비규정, 정비효과감시 프로그램

\begin{abstract}
Korea Hydro \& Nuclear Power Co. (KHNP) has developed and implemented the maintenance effectiveness monitoring (MR) programs for the operating nuclear power plants. MR programs are developed by reflecting design characteristics of the operating nuclear power plants to monitor the plant performance for improving the safety and reliability. Recently, KHNP has developed the MR program for APR1400 safety related systems to establish the advanced maintenance system and will verify the suitability of the MR program through evaluating initial performance. Consequently, it is expected that the safety of the new plant will be improved by developing and implementing the MR program.
\end{abstract}

Key words : Maintenance Rule, Maintenance Effectiveness Monitoring Program

\section{1. 서 론}

한수원은 선진 정비체계 구축을 통해 원전의 안전 성 및 신뢰성을 향상시킬 목적으로 정비효과감시 프

\footnotetext{
${ }^{\dagger}$ To whom corresponding should be addressed.

Korea Hydro \& Nuclear Power Company, Central Research Institute 25-1, Jang-dong, Yuseong-gu, Daejeon, Korea

Tel : 042-870-5633 E-mail : www@khnp.co.kr
}

로그램을 개발하여 2009년부터 가동 중인 경수로형 원전에서 이행하고 있으며, 2012년부터는 중수로형 원전까지 확대 적용하고 있다.

정비효과감시 프로그램은 일반적으로 정비규정 (MR, Maintenance Rule)이라 부르며, 발전소 전 계 통을 기능단위로 분류하여 발전설비에 대한 정비효과 를 감시한다. 현재 가동 중인 전 원전에서는 프로그 램 이행 효과를 높이기 위해 각 발전소별 고유 설계 
특성을 반영하여 최적화된 프로그램을 개발하였으며, 최근 건설을 완료한 신규원전의 경우에도 발전소 운 영 초기 단계부터 선진 정비체계 적기 구축을 위해 정비효과감시 프로그램 개발을 수행하였다 ${ }^{11}$.

따라서 본 논문에서는 국내 최초로 개발된 APR1400형 원전의 고유 설계특성을 반영한 안전관 련계통의 정비효과감시 프로그램 개발 프로세스와 주 요 특성을 제시하고자 한다.

\section{2. 정비효과감시 프로그램 개요}

정비효과감시 프로그램은 Fig.1에서 보는 바와 같 이 프로그램 개발 및 발전소 이행의 2 단계로 구분할 수 있다. 프로그램 개발 단계에서는 발전소 전 계통 에 대한 기능분류를 수행하고, 각 기능이 안전 또는 비안전 관련 기능에 해당되는지를 분석하여 프로그램 에서 관리할 대상 범위를 선정한다. 관리대상 범위 선정 후에는 확률론적안전성평가(PSA, Probabilistic Safety Assessment) 및 발전소 전문가들의 델파이 평 가 결과에 따라 프로그램에서 관리할 기능들에 대한 안전중요도를 결정(High 또는 Low)하고, 안전중요도, 기기 고장빈도 및 계통의 운전형태를 고려하여 신뢰 도성능기준(RPC), 이용도성능기준(APC), 상태감시성 능기준(CMC) 또는 호기수준성능기준(ULPC)을 수립 한다.

정비효과감시 프로그램 발전소 이행 단계에서는 수립된 성능기준을 기반으로 기기의 기능고장 또는

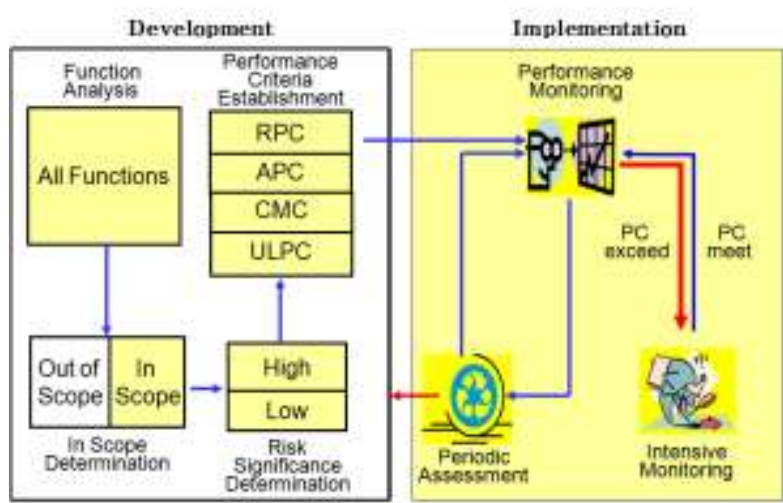

주) RPC (Reliability Performance Criteria), APC (Availability Performance Criteria), CMC (Condition Monitoring Criteria), ULPC (Unit Level Performance Criteria)

Fig. 1. Process diagram of maintenance effectiveness monitoring program
이용불능이 발생하는지 성능감시를 수행한다. 기능고 장 또는 이용불능시간의 누적 값이 성능기준에서 허 용하는 값을 초과하게 되면 발전소 전문가위원회에 서 집중감시를 결정하여 시정조치를 수행한다. 또한, 매 2년마다 정비효과감시 프로그램을 주기적으로 검 토 및 평가하여 프로그램을 최적화 시킨다.

\section{3. 정비효과감시 프로그램 개발 방향}

한수원은 미국 내 원전에서 적용한 NUMARC 93-01의 방법론 ${ }^{2}$ 을 기반으로 각 발전소별 고유 설계 특성을 반영하여 가동 중인 웨스팅하우스형 원전, OPR 1000 형 원전 및 중수로형 원전의 정비효과감시 프로그램 개발하였다 ${ }^{3}$ ). 따라서 국내 최초로 건설된 APR1400 안전관련계통 정비효과감시 프로그램은 Fig. 2에서 보는 바와 같이 NUMARC 93-01의 방법 론 및 가동 중인 원전의 프로그램 개발 시 축적된 경 험을 기반으로 고유 설계특성 검토, 각 계통별 기능 분석, 관리대상 범위 선정, 안전중요도 결정 및 성능 기준 수립 등을 수행하였다. 아울러 발전소 전문가위 원회에서 각 단계별 프로그램 개발 결과물을 상세 검 토 후 최종 승인함으로써 프로그램의 품질수준을 향 상시켰다.

\section{4. 정비효과감시 프로그램 개발}

\section{1 관리대상 범위 선정}

\subsection{1 관리대상 범위 선정 방법}

정비효과감시 프로그램은 $10 \mathrm{CFR} 50.65^{6)}$ 및 Reg. Guide $1.160^{7)}$ 에 따라 발전소를 기능단위로 감시하는 프로그램이며, 관리대상 범위 선정은 정비효과감시 프로그램에서 감시할 대상 기능을 결정하는 단계이 다. 즉, 발전소에서 기기수준의 성능감시를 수행하는 것은 감시자로 하여금 고장발생 시 바라보는 시각을 협소하게 해당 기기로만 국한되도록 하는 반면 기능 수준의 감시를 수행하면 해당 기능고장 시 전체 발전 소에 미치는 영향을 포괄적으로 평가하도록 감시 시 야를 넓혀줄 수 있다는 장점이 있다.

Fig.3은 APR1400 안전관련계통 정비효과감시 프 로그램의 기능분석 및 관리대상 범위 선정에 대한 흐 름도이다. 기능분석 단계에서는 APR1400형 원전의 안전성분석보고서, 운영기술지침서, 계통설명서, 설계 문서 및 계통도를 참조하여 안전관련계통들에 대한 


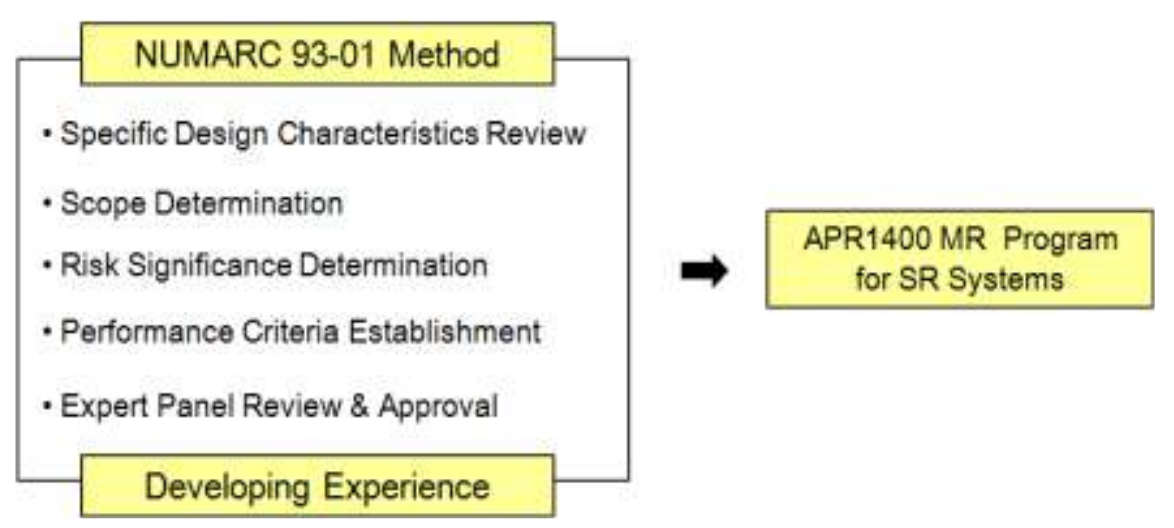

Fig. 2. Development diagram of program for APR1400 safety related systems

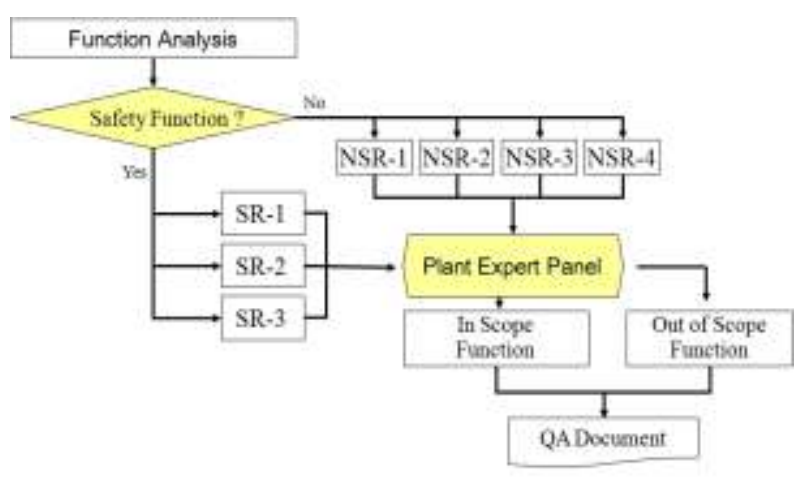

Fig. 3. Scope determination flow chart of the program

기능을 분류하고, 각 기능별로 고유 설계특성을 분석 하였다. 기능분석 수행 후에는 NUMARC 93-01의 방법론을 이용하여 각 기능이 안전관련 기능, 안전관 련 기능과 연관된 비안전관련 기능 또는 정비효과감 시 프로그램에서 관리할 필요가 없는 기능인지를 분 석하였다.

NUMARC 93-01에서 제시한 안전관련 기능의 범 주는 설계기준사고 시 원자로냉각재 압력경계의 건전 성 유지(SR-1), 원자로의 안전정지 및 안전정지 조건 유지(SR-2), 10CFR100 지침에 상응하는 잠재적 소 외 방사능 누출을 유발할 수 있는 사고결과를 방지 또는 완화(SR-3)하는 것이다. 비안전관련 기능은 안 전성분석보고서에 기술된 사고 또는 과도상태 완화 (NSR-1), 비상운전절차서에서 사용(NSR-2), 고장이 발생할 경우 안전관련 설비의 기능수행을 저해 (NSR-3), 고장이 발생할 경우 원자로 정지 또는 안전 관련 계통의 작동을 유발(NSR-4)하는 것이다. 정비 효과감시 프로그램에서는 안전관련 기능 및 비안전관 련 기능을 대상 범위에 포함시키며, 발전소 전문가위
원회에서 검토 후 APR1400 안전관련계통들의 관리 대상 범위를 최종 결정하였다. Table 1은 APR1400 안전관련계통의 기능분석 사례를 보여주고 있다.

\subsection{2 관리대상 범위 선정 특성}

APR1400 안전관련계통 정비효과감시 프로그램 개발 단계에서는 기존 OPR 1000 형 원전 대비 고유 설계특성 및 후쿠시마원전 사고 이후의 대응 설비들 에 대한 기능들이 추가되었으며, 기능분석 및 관리대 상 범위 선정 단계에서 OPR1000형 모델과 비교되는 프로그램의 주요 특성을 요약하면 다음과 같다.

첫째, OPR 1000 형에서는 3 대의 가압기안전밸브와 2 계열의 안전감압밸브가 원자로냉각재계통 과압보호 및 급속감압 기능을 수행하나, APR 1400 형에서는 가 압기 파이롯트구동 안전방출밸브(POSRV) 4대가 해 당 기능을 수행한다. 또한, OPR 1000 형에서는 가압기 보조살수 제공 밸브들이 다중으로 설계되었으나 APR1400형에서는 단일기기로 설치되었다.

둘째, 원자로건물 살수계통과 정지냉각계통이 열교 환기를 공유하는 OPR1000형과 달리 APR1400형에 서는 2 개의 계통 각각 열교환기를 독립적으로 설치하 였다.

셋째, 안전주입펌프 및 원자로건물 살수펌프에 붕 산수를 공급할 원자로건물내재장전수탱크(IRWST)를 설치하여 독립된 계통으로 분류하였으며, IRWST 설 치에 따라 사고후 급수/취출 운전 시 IRWST 냉각, 정지냉각펌프 운전 불가능시 IRWST 냉각 및 정화 기능이 추가되었다. 또한, 재순환작동신호 발생 기능 은 IRWST 설치에 따라 삭제하였다.

넷째, 공학적안전설비 펌프실 침수 방지 및 경보 제공 기능은 OPR1000형에서는 비관리대상으로 분석 
Table 1. Examples of function analysis

\begin{tabular}{|c|c|c|c|c|c|c|c|c|}
\hline \multirow{2}{*}{ Function ID } & \multirow{2}{*}{ Function Description } & \multicolumn{3}{|c|}{ SR } & \multicolumn{4}{|c|}{ NSR } \\
\hline & & 1 & 2 & 3 & 1 & 2 & 3 & 4 \\
\hline RC-01 & $\begin{array}{l}\text { Integrity of the reactor coolant system pressure } \\
\text { boundary }\end{array}$ & $\mathrm{Y}$ & $\mathrm{N}$ & $\mathrm{N}$ & $\mathrm{N}$ & $\mathrm{N}$ & $\mathrm{N}$ & $\mathrm{N}$ \\
\hline RC-04 & Reactor core cooling by natural circulation & $\mathrm{N}$ & Y & $\mathrm{N}$ & $\mathrm{N}$ & $\mathrm{N}$ & $\mathrm{N}$ & $\mathrm{N}$ \\
\hline SI-03 & Supplying safety injection water by SIT & $\mathrm{N}$ & $\mathrm{Y}$ & $\mathrm{N}$ & $\mathrm{N}$ & $\mathrm{N}$ & $\mathrm{N}$ & $\mathrm{N}$ \\
\hline CS-06 & Isolation of reactor building & $\mathrm{N}$ & $\mathrm{N}$ & $\mathrm{Y}$ & $\mathrm{N}$ & $\mathrm{N}$ & $\mathrm{N}$ & $\mathrm{N}$ \\
\hline CV-01 & Control of the reactor coolant system inventory & $\mathrm{N}$ & $\mathrm{N}$ & $\mathrm{N}$ & $\mathrm{N}$ & $\mathrm{Y}$ & $\mathrm{N}$ & $\mathrm{N}$ \\
\hline
\end{tabular}

Table 2. Results of in-scope determination

\begin{tabular}{c|c|c|c}
\hline \multicolumn{2}{c|}{ System } & \multicolumn{2}{c}{ Function } \\
\hline \hline Total & In Scope & Total & In Scope \\
\hline 21 & $17(80.9 \%)$ & 116 & $64(55.2 \%)$ \\
\hline
\end{tabular}

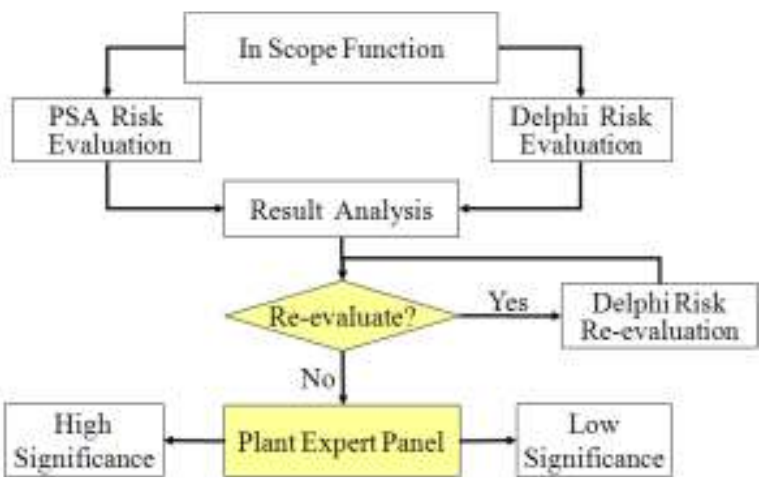

Fig. 4. Risk significance determination flow chart of the program

하였으나, APR 1400 형에서는 해당 기능상실 시 안전 관련펌프의 건전성에 영향을 미치므로 관리대상 기능 으로 선정하였다.

다섯째, 후쿠시마 원전 사고 이후 원자로용기 외벽 냉각, 비상 원자로건물 살수, 원자로공동 침수 기능 등이 추가되었으나, 설계기준사고보다는 중대사고 대 응 설비인 점을 고려하여 정비효과감시 프로그램에서 는 비관리 대상으로 분석하였다.

\subsection{3 관리대상 범위 선정 결과}

발전소 계통담당자들이 검토 및 보완 후 전문가위 원회에서 최종 결정한 안전관련계통 정비효과감시 프 로그램의 관리대상 기능 선정결과는 Table 2 와 같다. 총 21 개의 원자로 및 보조계통 중에서 17 개 $(80.9 \%)$ 의 안전관련계통이 관리대상이며, 나머지 계통은 비 관리대상으로 결정되었다. 또한, 총 116 개 기능 중에
서 64개(55.2\%) 기능이 정비효과감시 프로그램에서 관리할 대상으로 선정되었으며, 나머지 52개 기능은 비관리대상으로 결정되었다. 일반적으로 비관리대상 기능들은 원전의 안전성 및 신뢰성에 크게 영향을 미 치지 않는다.

\section{2 안전중요도 결정}

\subsection{1 안전중요도 결정 방법}

안전중요도 결정은 대상범위 선정 단계에서 정비 효과감시 프로그램의 관리대상으로 포함된 기능들에 대해 성능기준 및 성능감시 수준을 설정하기 위해 중 요도 High 또는 Low를 결정하는 것이다. 안전중요도 수준은 확률론적안전성평가(PSA)에 모델링된 경우, 노심손상빈도(CDF, Core Damage Frequency), 위험 도감소가치(RRW, Risk Reduction Worth) 및 위험도 증가가치(RAW, Risk Achievement Worth)의 중요도 정보를 활용한 정량적인 방법과 발전소 분야별 전문 가의 정성적인 델파이(Delphi) 평가 결과를 종합하여 전문가위원회에서 결정한다. 즉, 정량적인 평가와 정 성적인 평가간의 상호 보완을 통해 안전중요도 결정 의 객관성을 확보하기 위함이다.

Fig.4는 정비효과감시 프로그램의 안전중요도 결 정에 대한 흐름도이다. APR1400 안전관련계통 프로 그램의 안전중요도 결정 시는 OPR 1000 형 원전과 동 일하거나 유사한 기능들에 대해서는 OPR 1000 형 모 델 개발 경험을 참조하여 일관성이 유지될 수 있도록 하였다.

PSA 중요도 평가는 OPR1000형 모델과 APR 1400 형의 PSA 결과가 동일하지 않은 점을 고려하여 정비 효과감시 프로그램의 관리대상 범위로 선정된 64 개 기능 중 PSA에 모델링된 50 개의 기능들에 대해 $\mathrm{CDF}, \mathrm{RRW}$ 및 $\mathrm{RAW}$ 정보를 도출하여 Table 3 에 따 라 중요도를 평가하였다. PSA 중요도 평가결과, 중요 도 High는 21 개 기능, 중요도 Low는 29개 기능으로 
Table 3. Criteria of PSA risk significance evaluation

\begin{tabular}{c|c}
\hline $\begin{array}{c}\text { PSA } \\
\text { Significance }\end{array}$ & \multicolumn{1}{c}{ Criteria } \\
\hline \hline \multirow{3}{*}{ High } & $\bigcirc$ RRW $\geq 1.005$ or \\
& $\begin{array}{l}\bigcirc \text { RAW } \geq 2 \text { or } \\
\text { Including minimal cut set that } \\
\text { account for about } 90 \% \text { of the CDF }\end{array}$ \\
\hline \multirow{5}{*}{ Low } & $\bigcirc$ RRW $<1.005$ and \\
& $\begin{array}{l}\text { RAW }<2 \text { and } \\
\text { Not including minimal cut set that } \\
\text { account for about } 90 \% \text { of the CDF }\end{array}$ \\
\hline
\end{tabular}

Table 4. Criteria of PSA risk significance evaluation

\begin{tabular}{c|c}
\hline Delphi Significance & Criteria \\
\hline \hline High & Total Score $\geq 404$ \\
\hline Low & Total Score $<404$ \\
\hline
\end{tabular}

나타났다.

델파이(Delphi) 평가는 관리대상 범위로 선정된 64 개의 기능들을 대상으로 발전소 전문가들이 수행하였 으며, 정확한 평가 결과가 도출될 수 있도록 사전에 델파이 평가 기법 및 각 기능들의 주요특성에 대한 교육을 수행하였다. 델파이 평가 방법은 사고대응기 능 4 개 항목과 정상운전기능 6 개 항목에 대해 전문가 들이 평가를 수행한 후 결과를 취합하여 평균값을 계 산하고, 항목별 가중치를 곱하였으며, 경계치에 근접 한 값들에 대해서는 재평가를 수행한 후 Table 4에 따라 델파이 중요도를 평가하였다. 안전관련계통 총 64 개의 기능들 중 중요도 High는 19 개 기능, 중요도 Low는 45 개 기능으로 평가되었다.

발전소 전문가위원회에서는 PSA 및 델파이 중요 도 평가 결과를 검토한 후 안전중요도를 최종 결정하 였다. Table 5는 APR1400 안전관련계통의 안전중요 도 결정 사례를 보여주고 있다.

4.2.2 안전중요도 결정 특성

APR1400 안전관련계통 안전중요도 평가 단계에
서 이용한 PSA 정보는 OPR 1000 형 모델과 비교하여 상세분석을 수행하였고, APR1400형 원전의 운전경 험이 반영되지 않은 일반데이터를 사용하여 얻어진 결과라는 특징이 있다 ${ }^{8)}$. 그 결과 및 관리대상 범위 선정 단계에서 나타난 고유 설계특성에 따라 안전중 요도 결정 단계에서 OPR1000형 모델과 비교되는 프 로그램의 주요 특성을 요약하면 다음과 같다.

첫째, 안전주입펌프 및 원자로건물 살수펌프에 붕 산수를 공급할 원자로건물내재장전수탱크(IRWST)와 관련된 기능은 PSA 및 델파이 중요도 모두 High로 평가되어 안전중요도를 최종 High로 결정하였다.

둘째, 발전소 정상 및 비정상 조건하에서 원자로의 반응도를 제어하는 기능은 OPR 1000 형에서는 중요도 가 Low였으나, APR1400에서는 PSA 정보를 고려하 여 High로 정하였다.

셋째, 원자로냉각재계통의 저온 과압을 방지하는 기능의 경우 PSA에는 해당 기능이 모델링되어 있지 않아 델파이 중요도 평가 결과에 따라 Low가 되었다.

넷째, 원자로건물내재장전수탱크(IRWST)에 보충 수를 공급하고 반응도를 조절하는 기능은 PSA 중요 도 High, 델파이 중요도 Low로 평가되었으나 탱크 충수 유로가 다양하여 실제적으로 수위 상실 가능성 이 희박한 점을 고려 전문가위원회에서 Low로 결정 하였다.

다섯째, 원자로냉각재펌프에 냉각수를 공급하는 기 능의 경우 OPR1000형에서는 중요도가 High였으나, PSA 및 델파이 평가 결과를 고려 Low로 정하였다. 여섯째, 안전관련기기의 냉각을 위해 공급되는 기 기냉각수계통 열교환기와 관련된 기능은 PSA 중요도 Low, 델파이 중요도 High로 평가되었으나 해당 기능 이 중간방벽 역할을 수행하므로 전문가위원회 검토 후 최종 Low로 결정하였다.

4.2.3 안전중요도 결정 결과

발전소 전문가위원회 검토 후 최종 승인한 정비효

Table 5. Examples of risk significance determination

\begin{tabular}{c|c|c|c|c}
\hline \multirow{2}{*}{ Function ID } & \multirow{2}{*}{ Function Description } & \multicolumn{3}{|c}{ Risk Significance } \\
\cline { 2 - 5 } & & PSA & Delphi & Final \\
\hline \hline RC-01 & Integrity of the RCS pressure boundary & High & High & High \\
\hline RC-04 & Reactor core cooling by natural circulation & Low & High & High $^{*}$ \\
\hline SI-03 & Supplying safety injection water by SIT & High & High & High \\
\hline CS-06 & Isolation of reactor building & Low & Low & Low \\
\hline CV-01 & Control of the RCS inventory & Low & Low & Low \\
\hline
\end{tabular}


Table 6. Results of risk significance determination

\begin{tabular}{c|c|c|c|c|c|c|c}
\hline \multirow{2}{*}{$\begin{array}{c}\text { In-Scope } \\
\text { Function }\end{array}$} & \multicolumn{3}{|c|}{ PSA Significance } & \multicolumn{2}{c|}{ Delphi Significance } & \multicolumn{2}{c}{ Final Risk Significance } \\
\cline { 2 - 8 } & High & Low & None & High & Low & High & Low \\
\hline \hline 64 & 21 & 29 & 14 & 19 & 45 & 24 & 40 \\
\hline $100(\%)$ & 33 & 45 & 22 & 30 & 70 & 38 & 62 \\
\hline
\end{tabular}

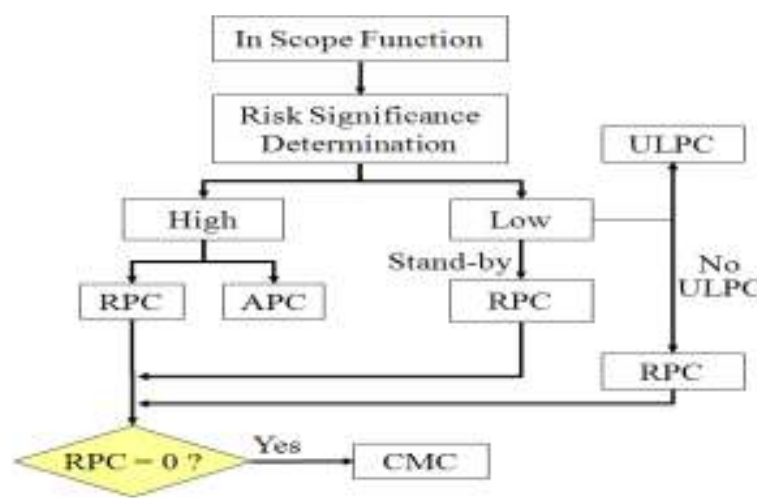

Fig. 5. Performance criteria establishment flow chart of the program

과감시 프로그램의 안전중요도 결정 결과는 Table 6 과 같다. APR1400 안전관련계통 정비효과감시 프로 그램의 관리대상 기능으로 선정된 64 개의 기능들 중 PSA에 모델링된 기능은 50개(78\%), 모델링되지 않 은 기능은 14 개(22\%)이다. PSA 모델링된 기능을 대 상으로 PSA 중요도를 평가한 결과, 중요도 $\mathrm{High}$ 는 21 개(33\%), 중요도 Low는 29개(45\%)로 나타났다. 델파이 평가는 안전관련계통 64 개 기능 전체를 대상 으로 수행한 결과, 중요도 High는 19개(30\%), 중요 도 Low는 45 개(70\%)로 나타났다. 발전소 전문가위 원회에서는 PSA 및 델파이 평가 결과를 검토한 후 최종적으로 64 개의 기능 중 안전중요도 High는 24개 $(38 \%), \quad$ Low는 $\quad 40$ 개(62\%)로 결정하였다.

\section{3 성능기준 수립}

\subsection{1 성능기준 수립 방법}

정비효과감시 프로그램의 관리대상 기능들에 대한 안전중요도가 결정되면 해당 기능들에 대한 성능감시 를 위해 성능기준을 수립하여야 한다. 성능기준은 안 전관련계통 관리대상 기능의 성능이 적절하게 발휘되 는지 확인하고 성능감시 목표를 설정하는데 필요하 다. 성능기준 설정수준 및 감시수준은 NUMARC
93-01에서 제시한 방법론에 따라 안전중요도와 운전 형태를 고려하여 신뢰도성능기준(RPC), 이용도성능 기준(APC), 상태감시성능기준(CMC) 또는 호기수준 성능기준(ULPC)을 수립하였다. APR1400 안전관련 계통 정비효과감시 프로그램 개발 시 성능기준 수립 단계에서는 OPR 1000 형 모델 개발 경험을 기반으로 관리대상 범위 선정 및 안전중요도 결정 시 나타난 APR1400형 원전의 고유 특성과 PSA 정보를 고려하 여 성능기준을 수립하였다. 총 64개 관리대상 기능들 간의 상호 연계성 분석 후 도출된 성능기준은 45 개이 며, 각 성능기준의 핵심기기 파악, 기능고장 정의 및 성능기준간의 경계를 설정하였다. 핵심기기란 해당 성능기준에서 기능고장을 유발하는데 큰 영향을 미치 는 기기로써 기능고장 정의 및 성능기준 수립을 위한 데이터 분석용 기초자료로 활용된다.

성능기준 설정수준은 NUMARC 93-01의 방법론 에 따라 안전중요도 High는 계열수준, 중요도 Low는 계통수준으로 정하였으며, 단일 계열로 구성된 기능 에 대해서는 안전중요도에 상관없이 계통수준으로 정 하였다. 또한, Fig. 5의 흐름도에서 보는 바와 같이 안전중요도가 $\mathrm{High}$ 인 경우에는 신뢰도성능기준 (RPC) 및 이용도성능기준(APC), 중요도가 Low이면 서 대기상태를 유지하는 경우는 신뢰도성능기준 (RPC)을 수립하였다. 안전중요도가 Low이면서 상시 운전되는 기능 중 NSR-4에 해당되는 기능은 호기수 준성능기준(ULPC), ULPC에 해당되지 않는 경우에 는 RPC를 수립하였다. 그리고 RPC가 "0"이거나 탱 크 등과 같이 상태감시가 적합한 경우에는 상태감시 성능기준 $(\mathrm{CMC})$ 을 수립하였다.

신뢰도성능기준(RPC)은 성능감시 기간 동안 허용되 는 기능고장(MRFF, Maintenance Rule Functional Failure) 수로 정의된다. 성능기준 설정값은 PSA에 모 델링된 경우와 PSA 유추(Surrogate) 및 확장 (Extension) 등 확대적용이 가능한 경우에는 EPRI 방 법론을 사용하였고, PSA 정보를 활용하여 성능기준을 수립할 수 없는 경우에는 안전중요도가 High이면 95\% 성공률, 중요도가 Low이면 $90 \%$ 성공률을 적용하였다. 
Table 7. Examples of performance criteria establishment

\begin{tabular}{c|c|c|c|c}
\hline PCID & Performance Criteria Description & $\begin{array}{c}\text { Risk } \\
\text { Significance }\end{array}$ & Level & $\begin{array}{c}\text { Performance } \\
\text { Criteria }\end{array}$ \\
\hline \hline RC01 & Integrity of the RCS pressure boundary & High & System & CMC :0 \\
\hline RC02 & Reactor core cooling by natural circulation & High & System & RPC : 1 \\
APC : 3 days \\
\hline SI03 & Supplying safety injection water by SIT & High & System & CMC1 : 0 \\
\hline PC02 & Isolation of reactor building & High & System & RPC : 0 \\
\hline CV01 & Control of the RCS inventory & Low & System & RPC : 1 \\
\hline
\end{tabular}

이용도성능기준(APC)은 관리대상 기능의 이용불 능시간(OOST, Out of Service Time)을 효율적으로 관리하기 위하여 수립하며, 성능기준 설정값은 운영 기술지침서의 허용정지시간(AOT, Allowed Outage Time), PSA 모델의 시험 및 정비사건에 대한 이용불 능도 데이터 및 운전경험을 반영하여 설정하였다.

상태감시성능기준 $(\mathrm{CMC})$ 은 기능고장 $(\mathrm{MRFF})$ 이나 예방가능기능고장(MPFF, Maintenance Preventable Functional Failure)을 허용할 수 없는 경우 및 피동 형 기기와 같이 상태감시가 효율적인 성능기준을 대 상으로 관련 절차서 및 관리 프로그램을 활용하여 성 능감시 방법을 수립하였다.

호기수준성능기준(ULPC)은 해당 기능이 비계획 발전정지, $30 \%$ 이상의 출력감발 및 공학적안전계통 작동에 해당되는 기능들에 대해 감시기간 3년 동안의 허용횟수를 부여하였다.

Table 7은 APR1400 안전관련계통 프로그램의 성 능기준 수립 사례를 보여주고 있다.

\subsection{2 성능기준 수립 특성}

$\mathrm{APR} 1400$ 안전관련계통 정비효과감시 프로그램의 성능기준 수립 단계에서 고유 설계특성 및 PSA 상세 분석에 따라 OPR 1000 형 모델과 비교되는 주요특성 을 요약하면 다음과 같다.

첫째, APR 1400 형 원전의 고유 설계특성 및 PSA 상세 분석에 따라 주요설비 고장률 데이터가 전반적 으로 낮은 수준이어서 RPC 및 APC 성능기준의 허 용값이 OPR1000형 모델과 비교하여 감소하였다.

둘째, 안전중요도 변경에 따라 중요도 Low로 관리 해야 하는 상시운전 기능들의 경우 APC 성능기준을 수립하지 않고, RPC 기준만을 수립하였다. 단, 해당 기능이 대기기능을 수행하면 PSA의 시험 및 정비데
Table 8. Results of risk significance determination

\begin{tabular}{c|c|c|c|c}
\hline \multirow{2}{*}{ Plant } & \multicolumn{3}{|c|}{ SR System Performance } & \multirow{2}{*}{ Total } \\
\cline { 2 - 4 } & $\begin{array}{c}\text { RPC / } \\
\text { APC }\end{array}$ & RPC & CMC & \\
\hline \hline APR1400 Model & 15 & 21 & 9 & 45 \\
\hline OPR1000 Model & 17 & 20 & 10 & 47 \\
\hline
\end{tabular}

이터가 존재할 때 APC 기준을 수립하였다.

셋째, 공학적안전설비 펌프에 붕산수를 공급할 원 자로건물내재장전수탱크(IRWST)와 관련된 성능기준 은 중요도 High이지만 정상운전 중 기능상실 시 정 비가 불가하므로 APC 기준을 수립하지 않았으며, $\mathrm{RPC}$ 허용값이 0 회로 계산되어 $\mathrm{CMC}$ 기준을 수립하 였다.

넷째, 원자로냉각재 재고량 제어를 감시하는 성능 기준은 OPR 1000 형 모델과 비교하여 펌프 운전 중 고장율이 크게 줄어들어 $\mathrm{RPC}$ 허용횟수가 감소하였 다.

다섯째, 기존 비상노심냉각계통 기기실 부압유지 및 배기 성능기준은 APR1400형에서는 설계특성을 고려 안전성 관련 기계기기실 냉각 기준으로 변경하 였다.

\subsection{3 성능기준 수립 결과}

APR1400 안전관련계통 정비효과감시 프로그램의 성능기준 수립 결과는 Table 8 과 같다. 안전관련계통 관리대상 기능으로 선정된 64 개 기능들의 상호 연계 성 분석 후 총 45 개의 성능기준을 수립하였으며, 최 종적으로 전문가위원회에서 $\mathrm{RPC} / \mathrm{APC}$ 를 함께 적용 하는 성능기준 15 개, $\mathrm{RPC}$ 만 적용하는 성능기준 21 개, $\mathrm{CMC}$ 를 적용하는 성능기준 9 개를 승인하였다. 
Table 8에서 APR1400 안전관련계통 성능기준과 OPR1000형 모델을 비교하여 본 결과, 고유 특성에 따라 상호간에 차이가 나타났으며, 향후 고장통지 및 오더를 이용하여 초기 성능평가를 수행함으로써 APR1400 안전관련계통 프로그램의 적합성을 입증할 것이다.

\subsection{4 정비효과감시 수행}

정비효과감시 프로그램을 이행 중인 기존 가동 중 원전의 경우, 감시 수행 중 기능고장이 발생하게 되 면, 발전소 엔지니어가 예방정비, 설비개선 및 정비방 법 등에 대한 타당성 검토를 수행하고, 기능고장 누 적으로 성능기준 초과 시에는 기능고장이 재발되지 않도록 집중감시 조치계획을 수립하여 시정조치를 수 행함으로써 안전/비안전관련 설비의 안전성 및 신뢰 성을 향상시키고 있다. APR1400 안전관련계통의 경 우에도 개발된 프로그램에 따라 초기 성능평가를 거 쳐 정비효과감시 프로그램 성능기준의 적합성이 입증 되면 발전소에 적용하여 성능감시를 수행함으로써 APR1400형 원전에 대한 대내·외 신뢰도를 제고시킬 것이다.

\section{5. 결 론}

본 논문에서는 APR 1400 형 원전의 선진 정비체계 구축을 위해 수행한 안전관련계통 정비효과감시 프로 그램 개발 프로세스 및 내용을 제시하였다.

첫째, 정비효과감시 프로그램을 이행 중인 가동중 원전과 비교하여 프로그램 개발 및 이행의 일관성을 확보하기 위해 동일한 방법론 및 OPR 1000 형 모델 개발 시 축적된 경험을 기반으로 개발하였다.

둘째, APR1400 안전관련계통의 고유 설계특성을 반영하여 정비효과감시 프로그램의 관리대상 범위선 정, 안전중요도 결정 및 성능기준을 수립하였다.

셋째, 성능기준 수립 후 OPR 1000 형 모델과 비교 하여 본 결과, 발전소 고유 특성에 따라 상호간에 차 이가 있었으며, 향후 누적된 고장통지 및 오더를 이 용하여 초기 성능평가를 수행함으로써 APR1400 안 전관련계통 정비효과감시 프로그램의 적합성을 입증 할 것이다.

결과적으로 정비효과감시 프로그램의 개발 및 이 행을 통해 발전소의 설계기능과 성능이 유지되고 있 는지 정비효과성을 감시함으로써 APR1400형 원전의
안전성 및 신뢰성이 향상될 것으로 기대되며, 향후, $\mathrm{UAE}$ 원전 등 수출형 원전 정비효과감시 프로그램 개발 시 표준모델로 활용될 것이다.

\section{References}

1. Yeom, D. U, Hyun, J. W, Song, T. Y, March 2012, "Development of Maintenance Effectiveness Monitoring Program Based Design Characteristics for New Nuclear Power Plant, pp $25 \sim 32$

2. Nuclear Energy Institute, July 2000, "Industry Guideline for Monitoring the Effectiveness of Maintenance at Nuclear Power Plants", NUMARC 93-01, Revision 3, pp 4 33

3. KHNP, July 2009, "Development of the Maintenance Rule Implementation Programs for Kori Units 1\&2", Final Report, pp 3 84

4. KHNP, July 2009, "Development of the Maintenance Rule Implementation Programs for OPR1000 Nuclear Power Plants", Final Report

5. Jerng, D. W., Chang, H. S., Ju, T. Y., April 2011, "Development of a Maintenance Effectiveness Monitoring Program for CANDU Reactors", Annals of Nuclear Energy, pp 1512 1518

6. Nuclear Regulatory Commission, July 1991, "Monitoring the Effectiveness of Maintenance at Nuclear Power Plants", 10CFR50.65, pp 1 $\sim 2$

7. Nuclear Regulatory Commission, June 1993, "Monitoring the Effectiveness of Maintenance at Nuclear Power Plants", Regulatory Guide 1.160 , pp $1 \sim 11$

8. KHNP, "Probabilistic Safety Assessment for Shin-kori Units 3\&4", Final Report 